\title{
Visual impairment in highly myopic eyes: the ZOC-BHVI high myopia cohort study
}

\author{
Yu Jiang MD, ${ }^{* 1}$ Decai Wang MD PhD, ${ }^{* 1}$ Xiaotong Han MD PhD, ${ }^{1}$ Chimei Liao \\ MD, ${ }^{1}$ Zhixi Li MD, ${ }^{1}$ J ane Scheetz PhD, ${ }^{2,3}$ Monica J ong PhD BOptom, ${ }^{4,5}$ Padmaja \\ Sankaridurg $\mathrm{PhD}^{4,5}$ and Mingguang He MD PhD',2,3 \\ *Co-first authors.
}

1. State Key Laboratory of Ophthalmology, Zhongshan Ophthalmic Center, Sun Yat-sen University, Guangzhou, China

2. Centre for Eye Research Australia, Royal Victorian Eye and Ear Hospital, Melbourne, Australia.

3. Ophthalmology, Department of Surgery, University of Melbourne, Melbourne, Australia.

4. Brien Holden Vision Institute, Sydney, New South Wales, Australia.

5. School of Optometry and Vision Science, UNSW, Australia.

Correspondence: Mingguang He, Zhongshan Ophthalmic Center, State Key Laboratory of Ophthalmology, Sun Yat-sen University, Guangzhou 510060, People's Republic of China.

E-mail: mingguang_he@yahoo.com

Short running title: Visual impairment in high myopes

This is the author manuscript accepted for publication and has undergone full peer review but has not been through the copyediting, typesetting, pagination and proofreading process, which may lead to differences between this version and the Version of Record. Please cite this article as doi: 10.1111/ceo.13779

This article is protected by copyright. All rights reserved. 
Received 29 October 2019; accepted 30 April 2020

Funding sources / Financial disclosure: This research was supported in part by a grant from the Fundamental Research Funds of the State Key Laboratory in Ophthalmology, National Natural Science Foundation of China [grant numbers 81420108008, 81271037 H1206], Science and Technology Planning Project of Guangdong Province [grant numbers 2013B20400003], Project funded by China Postdoctoral Science Foundation (2019TQ0365), and a grant from Brien Holden Vision Institute, Australia. Dr He receives support from the University of Melbourne Research Accelerator Program and the Centre for Eye Research Australia (CERA) foundation. CERA receives operational infrastructural support from the Victorian government. The sponsor or funding organization had no role in the study design, data collection, analysis, decision to publish, or preparation of the manuscript.

Conflict of interest: None 


\section{ABSTRACT}

I mportance: Understanding visual impairment (VI) under different definitions and potential risk factors in high myopic is important for future myopia control. Background: Limited studies exists investigating the $\mathrm{VI}$ among high myopic and with varying $\mathrm{VI}$ definitions.

Design: Registry cohort Study

Participants: 884 participants from ZOC-BHVI Study

Methods: Subjects aged 7-70 years with high myopia were enrolled. Uncorrected and best-corrected visual acuity (UCVA \& BCVA), cycloplegic refraction, axial length (AL), corneal curvatures, anterior chamber depth and lens thickness were measured. Axial length/Corneal radius of curvature ratio (AL/CR ratio) was calculated. Fundus lesions were graded into 5 categories. VI and blindness were defined based on the better-seeing eye according to the World Health Organization (WHO) criteria and United States (US) criteria. Multiple logistic regression analysis was used to assess risk factors for $\mathrm{VI}$.

Main outcome measures: Rates of $\mathrm{VI}$ and blindness

Results: A total of 884 participants were included, with mean (SD) age 18.5 (12.4) years and $46.4 \%$ male. Rate of $\mathrm{UCV} /$ blindness were $72.6 \% / 27.3 \%$ and $17.9 \% / 82.1 \%$ based on WHO and US criteria. With respect to BCVA, 4.1\%/ $5.9 \%$ of participants had BCVI using two definitions, while the rate for blindness was $0.2 \%$ and $0.6 \%$. After adjusting confounders, multiple logistic regression showed that more severe fundus lesions, greater AL/CR ratio were at a higher risk of being VI, both in two definitions $(p<0.005)$.

Conclusions and Relevance: The rate of $\mathrm{VI}$ and blindness in highly myopic patients varies significantly using different definition. Severe fundus lesions and greater AL/CR ratios were associated with a higher risk of VI. 
Keywords: visual impairment, blindness, rate, high myopia, WHO criteria, US criteria, risk factors

This article is protected by copyright. All rights reserved. 


\section{INTRODUCTI ON}

Myopia is the most common refractive disorders in the world, with the myopia prevalence continuing to increase globally in recent decades. ${ }^{1,2}$ It is estimated that more than 4.82 billion or $50 \%$ of the population worldwide will be affected by myopia by 2050 , among which $63 \%$ are Asian. ${ }^{3}$ Meanwhile, the prevalence of high myopia is also increasing dramatically, evidenced by previous reports that the prevalence of high myopia ranged $10 \%-16 \%$ in South Korea, ${ }^{4}$ Japan, ${ }^{5}$ and Singapore, ${ }^{6}$ even reach as high as $20 \%$ among school-aged Chinese populations in mainland China, ${ }^{7,8}$ Hongkong $^{9}$ and Taipei. ${ }^{10}$ It is no surprise that high myopia has becoming a growing public health concern, especially for regions where myopia prevalence are high.

According to the World Health Organization (WHO) , there were 253 million people with visual impairment (VI) and 36 million with blindness worldwide in 2017. ${ }^{11}$ High myopia related retinal degeneration has been reported to be the major cause of legal blindness in the Beijing Eye Study in China, ${ }^{12}$ the Tajimi Study in Japan ${ }^{5}$ and the Shihpai Eye Study in Taiwan, ${ }^{13}$ as well as a frequent cause of blindness in western countries. ${ }^{14,15}$ Unlike myopia, high myopia cannot simply be treated with a pair of spectacles, especially when pathologic ocular changes occur such as glaucoma, retinal detachment, and myopic maculopathy, all of which can cause irreversible vision loss. ${ }^{16,17}$

With the ever-increasing prevalence and higher risk of $\mathrm{VI}$ and blindness, high myopia is posing significant healthcare challenges around the world, especially in China which has the world's largest population and a rapidly increasing 
prevalence of high myopia. A greater understanding of VI status in those with high myopia is urgently needed to better guide preventative measures and future eyecare needs. However, few studies have reported the rate of $\mathrm{VI}$ and blindness among high myopes in China. Therefore, it is critical to explore the rate and related risk factors to enable adjustments to current public health strategies. The aim of this study is to assess $\mathrm{VI}$ in highly myopic eyes and the associated risk factors of those participating the ZOC-BHVI High Myopia Cohort Study in China.

\section{METHODS}

\subsection{Statement of ethics}

This study was approved by the institutional ethics committee of Zhongshan Ophthalmic Centre (2012KYNL002) and adhered to the Declaration of Helsinki for experimentation on human subjects. All participants or guardians of the participating children were informed of the study details and signed informed consent.

\subsection{Study Participants}

The study participants were enrolled in the ZOC-BHVI High Myopia Cohort Study and details of this cohort study have been described previously. ${ }^{18}$ In brief, it was a registry study in Zhongshan Ophthalmic Centre and initiated in 2011, which aimed to determine the development patterns of pathologies in highly myopic eyes. The optometry clinic with sufficiently resources, provides optical services for the public with nearly 300,000 visits per year. Nearly all patients with refractive problems need to go through an optometry clinic before being 
visited by an ophthalmologist. Thus, participants aged $7-70$ years with bilateral high myopia (defined as less than $-6.00 \mathrm{D}$ spherical power and no astigmatic cut-off was used) were invited to register for the study. Those with systemic or ocular disease (such as autoimmune conditions, cataracts, keratoconus, or myopia secondary to systemic disease), abnormal binocular vision including amblyopia and strabismus, history of intraocular or refractive surgery or myopia-control treatment were excluded from the study. Baseline data was collected from 2011 to 2012.

\subsection{Ophthalmic Examinations}

All subjects underwent a series of ophthalmic evaluations. Uncorrected visual acuity (UCVA) and best-corrected visual acuity (BCVA) were examined for each eye using the Early Treatment Diabetic Retinopathy Study (ETDRS) logMAR illiterate E VA chart (Precision Vision, Villa Park, Illinois, USA). Biometry measurements were carried out in a room with low ambient illumination by trained nurses. Axial length $(A L)$, corneal curvature $(C C)$, lens thickness (LT) and central anterior chamber depth (ACD) were measured before cycloplegia using an optical low-coherence reflectometry (Lenstar LS900; Haag-Streit AG, Koeniz, Switzerland). If AL exceeded the valid range of measurement in Lenstar ( $\geq 32 \mathrm{~mm}$ ), a repeated measurement was conducted using a partial coherence interferometry (IOLMaster, Carl Zeiss Meditec, Oberkochen, Germany). The mean of five AL measurements was taken as the final AL. Axial length/Corneal radius of curvature ratio (AL/CR ratio) was calculated. Cycloplegia was conducted using two drops of 0.5 per cent tropicamide five minutes apart for three times. A pupil size of more than 6 $\mathrm{mm}$ was considered successful dilation. Both objective and subjective 
refraction were examined 10 to 20 minutes after cycloplegia. Objective refraction was conducted with an auto-refractor (KR8800, Topcon, Tokyo, Japan), followed by a trial frame subjective refraction by an optometrist.

\subsection{Fundus Photography and Grading}

For all participants, two $45^{\circ}$ color fundus photographs centered at the macula and optic nerve were obtained using a digital retinal camera (Canon CX-1) after cycloplegia. Fundus photographs were graded according to the International Photographic Classification and Grading System for Myopic Maculopathy. ${ }^{19}$ Myopic maculopathy was classified into 5 categories of "no myopic retinal lesions" (category 0, C0), "tessellated fundus only" (category 1, C1), "diffuse chorioretinal atrophy" (category 2, C2), "patchy chorioretinal atrophy" (category 3, C3), and "macular atrophy" (category 4, C4). In addition, lesions including lacquer cracks, myopic choroidal neovascularization and Fuchs' spot were noted. Presence of staphyloma was identified based on fundus photographs by two independent graders who were masked to refraction data.

\subsection{Definition of Visual impairment and blindness}

According to the WHO definition, $\mathrm{VI}$ was defined as visual acuity (VA) $<20 / 60$ $\& \geq 20 / 400$ and blindness was defined as $V A<20 / 400$ in the better-seeing eye. $\mathrm{VI}$ and blindness were defined according to the United States (US) Standard in the same fashion, except that the cutoff for VI was 20/40 \& 20/200 and for blindness was 20/200. We calculated uncorrected visual impairment (UCVI) and best corrected visual impairment (BCV) based on uncorrected visual acuity (UCVA) and best-corrected visual acuity (BCVA), respectively. 


\subsection{Statistical Analysis}

Refractive error was calculated using the spherical equivalent (SE), calculated as spherical power plus half the cylindrical power. Age was categorized into 718 years, 19-39 years and $\geq 40$ years. High myopia was classified into 3 categories: -6.00 to $-7.99 \mathrm{D},-8.00-9.99 \mathrm{D}$, and $\geq-10.00 \mathrm{D}$. Axial length was classified into 3 categories: $<28.00 \mathrm{~mm}, 28.00$ to $29.99 \mathrm{~mm}$ and $\geq 30.00 \mathrm{~mm}$.

Median and 25th-75th percentile was used to describe the non-normal distribution parameters. Logistic regression analysis was used to assess the odds ratio (OR) of risk factors for $\mathrm{VI}$ and blindness. Univariate logistic regression analysis was conducted to examine the relationship between $\mathrm{BCVI}$ and confounders such as age, gender, $\mathrm{SE}, \mathrm{AL}, \mathrm{LT}$, fundus lesion severity and staphyloma. Since AL is significantly related to the SE in individuals, ${ }^{20} \mathrm{AL}$ was arbitrarily selected into the multiple analysis models to avoid collinearity. Similarly, fundus lesion severity is significantly related to staphyloma, so only fundus lesion level was included into the multiple regression analysis models. A p-value of $<0.05$ was considered statistically significant. All statistics were performed using STATA (V.14.0, Stata, College Station, Texas, USA).

\section{RESULTS}

A total of 890 subjects were enrolled in the ZOC-BHVI high myopia cohort study. Among these participants, 6 with co-existing retinal pathology in the best seeing eyes were excluded and the data from the remaining 884 subjects' best seeing eye were analyzed. The characteristics of the study population are presented in Table 1. Among 884 subjects, 410 (46.4\%) were male. The median age was 18.5 years (range, 7-70 years) and the median SE was -9.9 D 
(range, -6 to $-23.9 \mathrm{D}$ ). The median corneal curvature $(C C)$, axial length ( $A L)$, central anterior chamber depth (ACD) and lens thickness (LT) were 43.7 D, 27.4 $\mathrm{mm}, 3.2 \mathrm{~mm}$ and $3.6 \mathrm{~mm}$, respectively. The median Axial length/Corneal radius of

curvature ratio (AL/CR ratio) was 3.5 (range, 3.3-4.2).

Rates of BCVI and blindness are listed in Table 2. The rate of $\mathrm{BCV}$ and blindness using the WHO definition were $4.1 \%(2.8-5.4)$ and $0.2 \%(0-0.5)$, while that for the US criteria were $5.9 \%(4.3-7.4)$ and $0.6 \%(0.1-1.1)$, respectively. No significant difference was observed between gender for $\mathrm{BCV}$ $(p=0.525$ and $p=0.886)$ and blindness $(p=0.713$ and $p=0.668)$ under both $\mathrm{WHO}$ and US definition. The rates of BCVI were higher in subjects with myopia severe than $-10.0 \mathrm{D}$ and longer axial length (with all $p<0.001$ ).

Comparable results of the rates of UCVI and blindness are shown in Table 3. Using the WHO definition, $72.6 \%$ (69.7-75.6) participants fulfilled the criteria for UCVI, while $27.3 \%$ (24.3-30.2) subjects were blind. Using the U.S. definition, $17.9 \%$ (15.3-20.4) participants had UCVI, while 82.1\% (79.6-84.7) were blind. Participants older than 18 years of age presented a higher rate of blindness but lower rate of $\mathrm{BCV}$ (with all $\mathrm{p}<0.001$ ). The rate of blindness increased with more myopic SE and longer AL under both WHO and US criteria (with all $\mathrm{p}<0.001)$. Other results about rates of $\mathrm{BCVI} / \mathrm{UCVI}$ and blindness in the worseseeing eye are showed in Supplement table $1 \& 2$.

Figure 1 shows distribution of BCVA in different myopic maculopathy lesion categories (CO-C4) under WHO and US definitions according to age. In Figure 
$1 \mathrm{~A}$, the proportion of $\mathrm{BCVI}$ and blindness as the severity of myopic maculopathy lesion categories increased. An age-dependent increase in the proportion of $\mathrm{BCV}$ was also observed in each classification lesion. For blindness in C2 and C3+C4 group, no patient was observed in older age group. In Figure 1B, similar distributions of BCVI were also observed under US definition. But more proportion of blindness were observed in $\mathrm{C} 2$ and $\mathrm{C} 3+\mathrm{C} 4$ group. "Plus" lesions, which supplemented the Meta-PM categories, comprised lacquer cracks, choroidal neovascularization (CNV), and Fuchs spot. Among 884 participants, the occurrence of "plus" lesions were rare, present in only $18(2.0 \%)$ participants. Lacquer cracks, Fuchs spot, and CNV were found in 14 (1.6\%), 2 $(0.23 \%)$, and $2(0.23 \%)$ participants, respectively.

The relationship between $\mathrm{BCVI}$ and associated risk factors are shown in Table 4. Univariate logistic regression models showed that BCVI were significantly associated with increasing age, more myopic $\mathrm{SE}$, larger $\mathrm{CC}$, longer $\mathrm{AL}$, greater $A L / C R$ ratio, thicker $L T$, presence of staphyloma and more severe fundus lesions under both WHO and US criteria (with all $\mathrm{p}<0.05$ ). No association was found between $\mathrm{BCVl}$ and gender (WHO: $\mathrm{OR}=0.991, \mathrm{p}=0.788$; US: $\mathrm{OR}=0.968$, $p=0.148$ ) in neither criterion. Multiple regression models showed that subjects of female gender, with a greater AL/CR ratio had a higher risk of having BCVI under WHO definition. Similar significant associations were found between $\mathrm{BCV}$ and aforementioned confounders (with all $\mathrm{p}<0.05$ ), except for gender $(p=0.388$ ) when using US definition. Fundus lesion was an important risk factor since patients with fundus lesions had up to 10.5 or 26.7 times of higher risk of being visually impaired under US and WHO definition, respectively. 


\section{DISCUSSION}

Among 884 participants with high myopia in this study, we found that $4.1 \%$ $5.9 \%$ of high myopes had BCVI and $0.2-0.6 \%$ had blindness based on BCVA under the WHO and US criteria. As for UCVA, the rate of VI and blindness was $72.6 \%$ and $27.3 \%$ using the WHO criteria and $17.9 \%$ and $82.1 \%$ using the US criteria, respectively. More severe fundus lesions, longer $\mathrm{AL}$ and larger $\mathrm{CC}$ were significant risk factors for both $\mathrm{BCV}$ and UCVI.

Few researches have reported the rate of $\mathrm{VI}$ and blindness in high myopes. Shih et al ${ }^{21}$ included 552 high myopes in Taiwan and reported that the rate of BCVI was $10 \%$ in patients aged 40 to 59 and $56 \%$ in those older than 60 . The Handan Eye Study found that in high myopes (SE <-5.0D), BCVI existed in 14 participants (24.6\%) over 30 years of age using the WHO definition. ${ }^{22}$ The rate of BCV was $4.1 \%$ in our study, which is much lower than that in the above two studies. This may be attributed to differences in the studied populations, since participants in our study were much younger ( $6-70$ vs. $>40 \&>30$ years old) when myopia and related pathologic changes were still likely to be progressing. We would expect to see a rise in BCVI in our study population as they continue to age. But with increasing public awareness and scientific advances in the treatment of high myopia around the word, myopia-related complications and $\mathrm{BCV}$ will decrease in the future.

It's worth mentioning that the rate of blindness based on UCVA under US criteria was much higher than the WHO criteria ( $72.6 \%$ vs. $17.9 \%$ ), which suggests that most subjects VA ranged from $20 / 60$ to $20 / 200$ and using a 
different criterion for $\mathrm{Vl}$ and blindness would have a significant impact on rate estimates. For UCVI, more studies are required to verify this. We need take precautions when comparing prevalence among different countries and regions. The US definition better reflects the visual demands of modern urban life, such as driving a car and viewing a screen, which require a higher level of vision and therefore require a stricter definition of $\mathrm{V}$.

Older age has been considered a major risk factor for BCVI in many studies, ${ }^{12,23}$ which is inconsistent with our study. The difference may be largely attributed to the skewed distribution of age in our population, since half of the population were under 19 years of age. Compared to patients with older age and longer duration of high myopia, young patients are less likely to develop myopic maculopathy which is one of the most important causes of vision impairment. What's more, age is significantly associated with ocular biometrics such as AL and ACD in the growth stage. Therefore, collinearity may severely affect the estimation for the relationship between age and visual impairment, evidenced by the fact that the association between age and BCV became insignificant after adjusting ocular biometrics and the severity of fundus lesions. However, future follow-up studies are required to confirm this association.

In the present study, we found that the risk of BCVI in high myopia was 2.4 times higher in females than males $(p=0.048)$. Some studies also revealed a stronger association between female and $\mathrm{VI},{ }^{24}$ but not in others. ${ }^{23,25} \mathrm{~A}$ possible explanation is that Asian women tend to avoid direct sun exposure and spend more time performing near tasks indoors compared to men. Meanwhile, the effect of sex hormones on ocular structures may be another potential 
mechanism. Estrogen is related to myopia progression, possibly due to scleral remodeling through metalloproteinases. ${ }^{26}$ So higher prevalence of myopia and high myopia in woman are more likely related to higher VI.

A higher risk of myopic maculopathy or VI was associated with severe myopia levels among adults in other studies. ${ }^{27,28}$ Similarly, our findings indicate that individuals with more severe myopia have a higher risk of BCVI. Its rate increased markedly with higher levels of myopia.

AL was significantly associated with $\mathrm{VI}$ among high myopes, which has also been reported in previous studies. ${ }^{29,30} \mathrm{~A}$ number of reports have shown a negative relationship between AL and SE. A higher risk of myopic maculopathy, which can cause irreversible $\mathrm{VI}$, was associated with greater myopic SE among adults. ${ }^{30} \mathrm{AL}$ reflects the sum of the anterior chamber depth (ACD), lens thickness (LT) and vitreous chamber depth (VCD). Research has shown that part of the heritability of $A L$ is mediated by $A C D .{ }^{20}$ So $A C D$ and $L T$ as two of the influencing factors were included in the analysis and were significantly associated with BCVI in the univariate logistic regression model. But they were not identified as a risk factor for BCVI in our study population. It is suggested that VCD has the greatest contributing effect, when individual components of $A L$ are evaluated and this is also supported by previous studies. ${ }^{31}$ We found that a higher risk of $\mathrm{BCV}$ was associated with larger CC in our study, which is similar to the study by Wu et al (CIEMS; 4711 adults). ${ }^{32}$ And AL/CR ratio is a strong predictor for BCVI in our study. The AL/CR ratio is a more robust measure of the refractive status of the eye because it minimizes the variability between them. Thus, it can be a useful marker of the onset and the progression 
of myopia, especially among high myopia patients. ${ }^{33}$ The correlation between $\mathrm{AL}$ and $\mathrm{CC}, \mathrm{SE}$ and $\mathrm{CC}$ are strong and positive, while the correlation between AL/CR ratio and SE are negative. With the progression of myopia and AL elongation, corneal radius of curvature becomes steeper and corneal refractive power increases. ${ }^{34}$

Age is an important factor for myopic maculopathy and therefore we analyzed the BCVA in two age subgroups, 7-39 yrs and older than 40 yrs. ${ }^{30}$ We found that BCVI and blindness tended to be more common for patients older than 40 years of age than younger age group in $\mathrm{C} 0, \mathrm{C} 1, \mathrm{C} 2$ group both definitions. But in C3+C4 group of our study, a small number of total patients led us to fail to reach the same conclusion yet. In addition, our results indicated that severer myopic maculopathy group had more BCVI and blindness, similarly to other studies. ${ }^{27,28}$

The presence of any myopic maculopathy was associated with BCVI in our study, which is supported by previous studies. ${ }^{27,30} \mathrm{It}$ is the main risk factor of BCVI in myopic eyes. We also found that there is a non-linear increase in the risk of $\mathrm{BCV}$ from $\mathrm{CO}$ to $\mathrm{C} 4$. Morphologic changes in the posterior region of the eye, such as diffuse and localized chorioretinal atrophic lesions are often associated with choroidal thinning, making it susceptible to retinal degeneration, retinal holes, and choroidal neovascularization (CNV) and other fundus lesions which may result in loss of central vision. High myopes have thinner sclera that may be due to both reduced collagen synthesis and increased collagen degradation. All this suggests that prevention of $\mathrm{VI}$ requires more attention to myopic 
macular retinopathy. Staphyloma presents more stretching of the macular lesion, which may explain the higher $\mathrm{VI}$ of more severe myopic maculopathy. ${ }^{35}$

The strengths of this study include a large sample size of high myopes from South China, standardized methodology for data collection and comprehensive ophthalmic examinations including refraction, ocular biometry assessment and fundus photography. We employed the latest standardized International photographic classification and grading system classification ${ }^{18}$ to categorize myopic maculopathy, enhancing the comparability of other findings. ${ }^{3}$ Furthermore, the rate of $\mathrm{V}$ and blindness was reported in detail using BCVA and UCVA under the WHO and US definitions, which provides a better understanding of the $\mathrm{VI}$ in high myopes.

There are several limitations of our study that should be taken into consideration. Firstly, our research was conducted based on a previous registry study rather than a population-based study. However, considering the low prevalence of high myopia in Sothern China, a registry study is a relatively more efficient and cost-effective design to investigate risk factors for $\mathrm{VI}$ in high myopia. Secondly, specific causes of $\mathrm{VI}$ and blindness in highly myopic patients were not determined in this study. However, we tried to explore the risk factors of $\mathrm{VI}$ in respect to ocular structures and fundus lesions, which provides information on cause analysis. We found $\mathrm{CO}$ to $\mathrm{C} 4$ were significantly associated with BCVI, which is supported by findings from previous studies. ${ }^{30}$ We believe the main cause of $\mathrm{BCV}$ to be pathological fundus lesions. Using the US definition, $94.1 \%$ of the study participants could achieve VA $\geq 20 / 40$ with best refractive correction, meaning refractive error is the primary cause of UCVI. 
Lastly, no additional variables such as educational level, family income, near work time were added to the analysis.

\subsection{Conclusion}

We observed high rate of $\mathrm{UCVI}$ and $\mathrm{BCV}$ among high myopes in China, which is expected to increase with the aging population. Greater AL/CR ratio and more severe fundus lesions were associated with a higher risk of BCVI. Increased efforts are required to promote eye care services for high myopes who are at higher risk of $\mathrm{VI}$. 


\section{REFERENCES}

1. Dolgin E. The myopia boom. Nature 2015; 519: 276-8.

2. Holden BA, Fricke TR, Wilson DA, J ong M, Naidoo KS, Sankaridurg P, Wong TY, Naduvilath TJ, Resnikoff S. Global Prevalence of Myopia and High Myopia and Temporal Trends from 2000 through 2050. Ophthalmology 2016; 123: 1036-42.

3. Morgan IG, French AN, Ashby RS, Guo X, Ding X, He M, Rose KA. The epidemics of myopia: Aetiology and prevention. Progress in retinal and eye research 2018; 62: 134-49.

4. Lee JH, Jee D, Kwon JW, Lee WK. Prevalence and risk factors for myopia in a rural Korean population. Investigative Ophthalmology \& Visual Science 2013; 54: 5466-71.

5. I wase A, Araie M, Tomidokoro A, Yamamoto T, Shimizu H, Kitazawa Y. Prevalence and causes of low vision and blindness in a J apanese adult population: the Tajimi Study. Ophthalmology 2006; 113: 1354-62.

6. Wu HM, Seet B, Yap EP, Saw SM, Lim TH, Chia KS. Does education explain ethnic differences in myopia prevalence? A population-based study of young adult males in Singapore. Optometry and vision science : official publication of the American Academy of Optometry 2001; 78 : 234-9.

7. He M, Huang W, Zheng Y, Huang L, Ellwein LB. Refractive error and visual impairment in school children in rural southern China. Ophthalmology 2007; 114: 374-82. 
8. He M, Zeng J, Liu Y, Xu J, Pokharel GP, Ellwein LB. Refractive error and visual impairment in urban children in southern china. Investigative Ophthalmology \& Visual Science 2004; 45: 793-9.

9. Fan DS, Lam DS, Lam RF, Lau JT, Chong KS, Cheung EY, Lai RY, Chew SJ . Prevalence, incidence, and progression of myopia of school children in Hong Kong. Investigative Ophthalmology \& Visual Science 2004; 45: 1071-5.

10. Lin LL, Shih YF, Hsiao CK, Chen CJ. Prevalence of myopia in Taiwanese schoolchildren: 1983 to 2000. Annals of the Academy of Medicine, Singapore 2004; 33: 27-33.

11. WHO. Visual impairment and blindness fact sheet. 2017. Visual impairment and blindness fact sheet 2017.

12. Xu L, Wang Y, Li Y, Wang Y, Cui T, Li J, J onas J B. Causes of blindness and visual impairment in urban and rural areas in Beijing: the Beijing Eye Study. Ophthalmology 2006; 113: 1134.e1-11.

13. Hsu WM, Cheng CY, Liu JH, Tsai SY, Chou P. Prevalence and causes of visual impairment in an elderly Chinese population in Taiwan: the Shihpai Eye Study. Ophthalmology 2004; 111: 62-9.

14. Buch H, Vinding T, La Cour M, Appleyard M, Jensen GB, Nielsen NV. Prevalence and causes of visual impairment and blindness among 9980 Scandinavian adults: the Copenhagen City Eye Study. Ophthalmology 2004; 111: 53-61.

15. Cedrone C, Culasso F, Cesareo M, Nucci C, Palma S, Mancino R, Cerulli L. Incidence of blindness and low vision in a sample population: the Priverno Eye Study, Italy. Ophthalmology 2003; 110: 584-8. 
16. Wong TY, Ferreira A, Hughes R, Carter G, Mitchell P. Epidemiology and disease burden of pathologic myopia and myopic choroidal neovascularization: an evidence-based systematic review. American journal of ophthalmology 2014; 157: 9-25.e12.

17. Verkicharla PK, Ohno-Matsui K, Saw SM. Current and predicted demographics of high myopia and an update of its associated pathological changes. Ophthalmic \& physiological optics : the journal of the British College of Ophthalmic Opticians (Optometrists) 2015; 35: 465-75.

18. Chen $Y$, Xiao O, Guo X, Wang D, Sankaridurg P, Morgan I, He M. Methodology of the ZOC-BHVI High Myopia Cohort Study: The Onset and Progression of Myopic Pathologies and Associated Risk Factors in Highly Myopic Chinese. Ophthalmic epidemiology 2018; 25: 31-8.

19. Ohno-Matsui K, Kawasaki R, J onas JB, Cheung CM, Saw SM, Verhoeven VJ, Klaver CC, Moriyama M, Shinohara K, Kawasaki Y, Yamazaki M, Meuer S, Ishibashi T, Yasuda M, Yamashita H, Sugano A, Wang JJ, Mitchell P, Wong TY. International photographic classification and grading system for myopic maculopathy. American journal of ophthalmology2015; 159: 877-83.e7.

20. Klein AP, Suktitipat B, Duggal P, Lee KE, Klein R, Bailey-Wilson JE, Klein BE. Heritability analysis of spherical equivalent, axial length, corneal curvature, and anterior chamber depth in the Beaver Dam Eye Study. Archives of ophthalmology (Chicago, III : 1960) 2009; 127: 649-55.

21. Shih YF, Ho TC, Hsiao CK, Lin LL. Visual outcomes for high myopic patients with or without myopic maculopathy: a 10 year follow up study. The British journal of ophthalmology 2006; 90: 546-50. 
22. Gao LQ, Liu W, Liang YB, Zhang F, Wang JJ, Peng Y, Wong TY, Wang NL, Mitchell P, Friedman DS. Prevalence and characteristics of myopic retinopathy in a rural Chinese adult population: the Handan Eye Study. Archives of ophthalmology (Chicago, IIl : 1960) 2011; 129: 1199-204.

23. Rim TH, Nam JS, Choi M, Lee SC, Lee CS. Prevalence and risk factors of visual impairment and blindness in Korea: the Fourth Korea National Health and Nutrition Examination Survey in 2008-2010. Acta Ophthalmologica 2014; 92: e317-25.

24. Zhao J, Ellwein LB, Cui H, Ge J, Guan H, Lv J, Ma X, Yin J, Yin ZQ, Yuan Y, Liu H. Prevalence of vision impairment in older adults in rural China: the China Nine-Province Survey. Ophthalmology 2010; 117: 409-16, 16.e1.

25. Xu L, Li Y, Wang S, Wang Y, Wang Y, J onas J B. Characteristics of highly myopic eyes: the Beijing Eye Study. Ophthalmology 2007; 114: 121-6.

26. Lyu IJ, Kim MH, Baek SY, Kim J, Park KA, Oh SY. The Association Between Menarche and Myopia: Findings From the Korean National Health and Nutrition Examination, 2008-2012. Investigative Ophthalmology \& Visual Science 2015; 56: 4712-8.

27. Chen SJ, Cheng CY, Li AF, Peng KL, Chou P, Chiou SH, Hsu WM. Prevalence and associated risk factors of myopic maculopathy in elderly Chinese: the Shihpai eye study. Investigative Ophthalmology \& Visual Science 2012; 53: 4868-73.

28. Liu HH, Xu L, Wang YX, Wang S, You QS, J onas JB. Prevalence and progression of myopic retinopathy in Chinese adults: the Beijing Eye Study. Ophthalmology 2010; 117: 1763-8. 
29. Tideman J W, Snabel MC, Tedja MS, van Rijn GA, Wong KT, Kuijpers RW, Vingerling J R, Hofman A, Buitendijk GH, Keunen JE, Boon C), Geerards Al , Luyten GP, Verhoeven VJ, Klaver CC. Association of Axial Length With Risk of Uncorrectable Visual Impairment for Europeans With Myopia. JAMA Ophthalmology 2016; 134: 1355-63.

30. Wong $Y L$, Sabanayagam $C$, Ding $Y$, Wong CW, Yeo AC, Cheung YB, Cheung G, Chia A, Ohno-Matsui K, Wong TY, Wang JJ, Cheng CY, Hoang QV, Lamoureux E, Saw SM. Prevalence, Risk Factors, and Impact of Myopic Macular Degeneration on Visual Impairment and Functioning Among Adults in Singapore. Investigative Ophthalmology \& Visual Science 2018; 59: 4603-13.

31. Richter GM, Wang M, Jiang X, Wu S, Wang D, Torres M, Choudhury F, Varma R. Ocular Determinants of Refractive Error and Its Age- and SexRelated Variations in the Chinese American Eye Study. JAMA Ophthalmology 2017; 135: 724-32.

32. Nangia V, Jonas J B, Sinha A, Matin A, Kulkarni M, Panda-J onas S. Ocular axial length and its associations in an adult population of central rural India: the Central India Eye and Medical Study. Ophthalmology 2010; 117: $1360-6$.

33. Jong M, Sankaridurg P, Naduvilath TJ, Li W, He M. The Relationship between Progression in Axial Length/Corneal Radius of Curvature Ratio and Spherical Equivalent Refractive Error in Myopia. Optometry and vision science : official publication of the American Academy of Optometry 2018; 95: 921-9. 
34. Goss DA, Erickson P. Meridional corneal components of myopia progression in young adults and children. AmJ Optom Physiol Opt 1987; 64: 475-81.

35. Guo X, Xiao O, Chen Y, Wu H, Chen L, Morgan IG, He M. ThreeDimensional Eye Shape, Myopic Maculopathy, and Visual Acuity: The Zhongshan Ophthalmic Center-Brien Holden Vision Institute High Myopia Cohort Study. Ophthalmology 2017; 124: 679-87. 
Table 1: Study population characteristics

\begin{tabular}{llll}
\hline Variables & Median & $\begin{array}{l}25 \%-75 \% \\
\text { Percentiles }\end{array}$ & Range \\
\hline
\end{tabular}

\begin{tabular}{llll}
\hline Male (\%) & 410 & & \\
Age (yrs) & $(46.4)$ & & $7 \sim 70$ \\
SE (D) & 18.5 & $14.2 \sim 27.6$ & $-23.9 \sim-6.0$ \\
AL (mm) & -9.9 & $-11.0 \sim-7.5$ & $23.8 \sim 34.3$ \\
CC (D) & 27.4 & $26.3 \sim 28.2$ & $38.6 \sim 50.5$ \\
AL/CR ratio & 43.7 & $42.8 \sim 44.8$ & $3.3 \sim 4.2$ \\
ACD (mm) & 3.5 & $3.4 \sim 3.6$ & $1.9 \sim 3.9$ \\
LT (mm) & 3.2 & $3.0 \sim 3.3$ & $2.8 \sim 5.5$ \\
\hline
\end{tabular}

D: Diopter; mm: millimeter; CC: Corneal Curvature; AL: Axial Length; SE: Spherical Equivalent; ACD: Anterior Chamber Depth; LT: Lens Thickness

AL/CR ratio: Axial Length ( $\mathrm{mm})$ / Corneal radius ( $\mathrm{mm})$ 
Table 2: Rates of best-corrected visual impairment and blindness in better-seeing eye (Defined by WHO criteria and US criteria) by gender, age, spherical equivalent and axial length. 


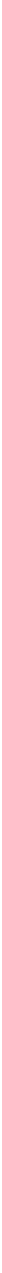




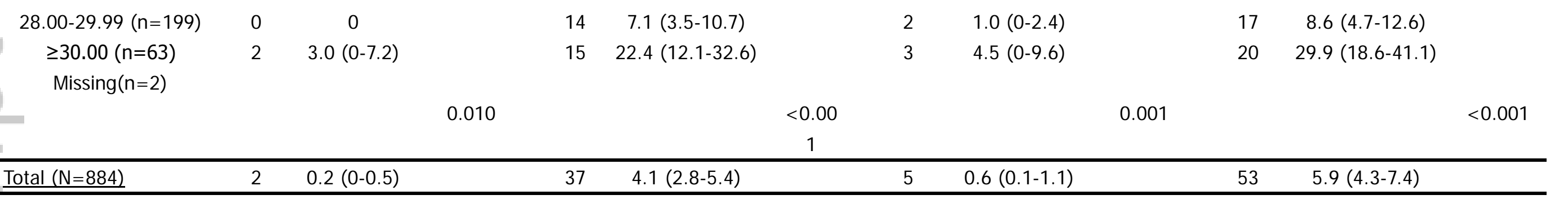

D: Diopter; WHO: World Health Organization criteria; US: United States criteria

Table 3: Rates of uncorrected visual impairment and blindness in better-seeing eye (Defined by WHO criteria and US criteria) by gender, age, spherical equivalent and axial length in ZOC-BHVI High Myopia Cohort Study.

\begin{tabular}{|c|c|c|c|c|c|c|c|c|c|c|c|c|}
\hline \multirow{3}{*}{ Group } & \multicolumn{6}{|c|}{ Visual Acuity in the Better-Seeing Eye (WHO) } & \multicolumn{6}{|c|}{ Visual Acuity in the better-Seeing Eye (US) } \\
\hline & \multicolumn{3}{|c|}{$<20 / 400$} & \multicolumn{3}{|c|}{$<20 / 60$ and $\geq 20 / 400$} & \multicolumn{3}{|c|}{$<20 / 200$} & \multicolumn{3}{|c|}{$<20 / 40$ and $\geq 20 / 200$} \\
\hline & No. & $\%(95 \% \mathrm{Cl})$ & $P$ & No. & $\%(95 \% \mathrm{Cl})$ & $P$ & No. & $\%(95 \% \mathrm{Cl})$ & $P$ & No. & $\%(95 \% \mathrm{Cl})$ & $P$ \\
\hline Gender & & & & & & & & & & & & \\
\hline Male $(n=410)$ & 116 & $28.3(23.9-32.7)$ & & 294 & $71.7(67.3-76.1)$ & & 331 & 80.7 (76.9-84.6) & & 79 & $19.3(15.4-23.1)$ & \\
\hline Female $(n=474)$ & 125 & $26.4(22.4-30.4)$ & & 348 & $73.4(69.4-77.4)$ & & 395 & $83.3(80.0-86.7)$ & & 79 & $16.7(13.3-20.0)$ & \\
\hline & & & 0.545 & & & 0.597 & & & 0.333 & & & 0.333 \\
\hline Age & & & & & & & & & & & & \\
\hline $7-18(n=426)$ & 76 & $17.8(14.2-21.5)$ & & 349 & $81.9(78.3-85.6)$ & & 323 & 75.8 (71.7-79.9) & & 103 & $24.2(20.1-28.3)$ & \\
\hline $19-39(n=362)$ & 134 & $37.0(32.0-42.0)$ & & 228 & $63.0(58.0-68.0)$ & & 320 & 88.4 (85.1-91.7) & & 42 & $11.6(8.3-14.9)$ & \\
\hline
\end{tabular}


$40+(n=96)$
$31 \quad 32.3(22.8-41.8)$
$<0.00$

1

65

$67.7(58.2-77.2) \quad<0.00$

1 28.00-29.99 $(n=199)$

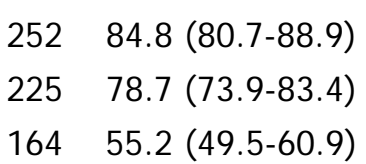

$<0.00$

1

$\begin{array}{ccc} & 252 & 84.8(80.7-88.9) \\ & 225 & 78.7(73.9-83.4) \\ & 164 & 55.2(49.5-60.9) \\ <0.00 & & \\ 1 & & \\ & & \\ & 495 & 80.1(76.9-83.3) \\ & 122 & 61.9(55.1-68.8) \\ & 25 & 37.3(25.4-49.2)\end{array}$

$<0.00$

1
Axial Length $(\mathrm{mm})$

$<28.00(n=620)$ $\geq 30.00(n=63)$ Missing $(n=2)$

$44 \quad 14.8(10.8-18.9)$

$61 \quad 21.3(16.6-26.1)$

$13344.8(39.1-50.5)$

$<-10.00(n=294)$

Missing $(n=4)$

$\begin{array}{cc}122 & 19.7(16.6-22.9) \\ 75 & 38.1(31.2-44.9) \\ 42 & 62.7(50.8-74.6)\end{array}$

$<0.00$

1

$241 \quad 27.3(24.3-30.2)$

Total $(\mathrm{N}=884)$
$13 \quad 13.5(6.6-20.5)$

$<0.00$

1

$<0.00$

1

$\begin{array}{ll}215 & 72.4(67.3-77.5) \\ 239 & 83.6(79.2-87.9) \\ 268 & 90.2(86.8-93.6)\end{array}$

$82 \quad 27.6(22.5-32.7)$

$47 \quad 16.4(12.1-20.8)$

$29 \quad 9.8(6.4-13.2)$

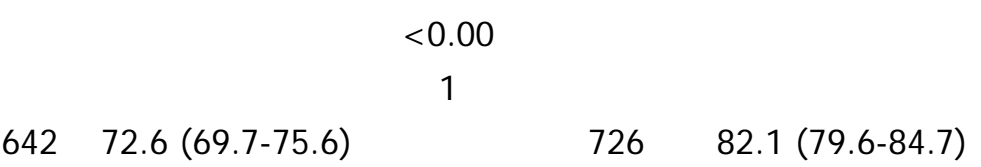

$<0.00$

$<0.00$

1
$486 \quad 78.6(75.4-81.9)$
$172 \quad 87.3(82.6-92.0)$
$66 \quad 98.5(95.5-100.0)$
$132 \quad 21.4$ (18.1-24.6)
$25 \quad 12.7(8.0-17.4)$
$1 \quad 1.5(0-4.5)$

$<0.00$

$<0.00$

1

$158 \quad 17.9(15.3-20.4)$

D: Diopter; WHO: World Health Organization criteria; US: United States criteria

Table 4: Logistic regression analysis of risk factors for visual impairment. (BCVA $<20 / 60$ and $\geq 20 / 400$, WHO; $B C V A<20 / 40$ and $\geq 20 / 200$ ) 


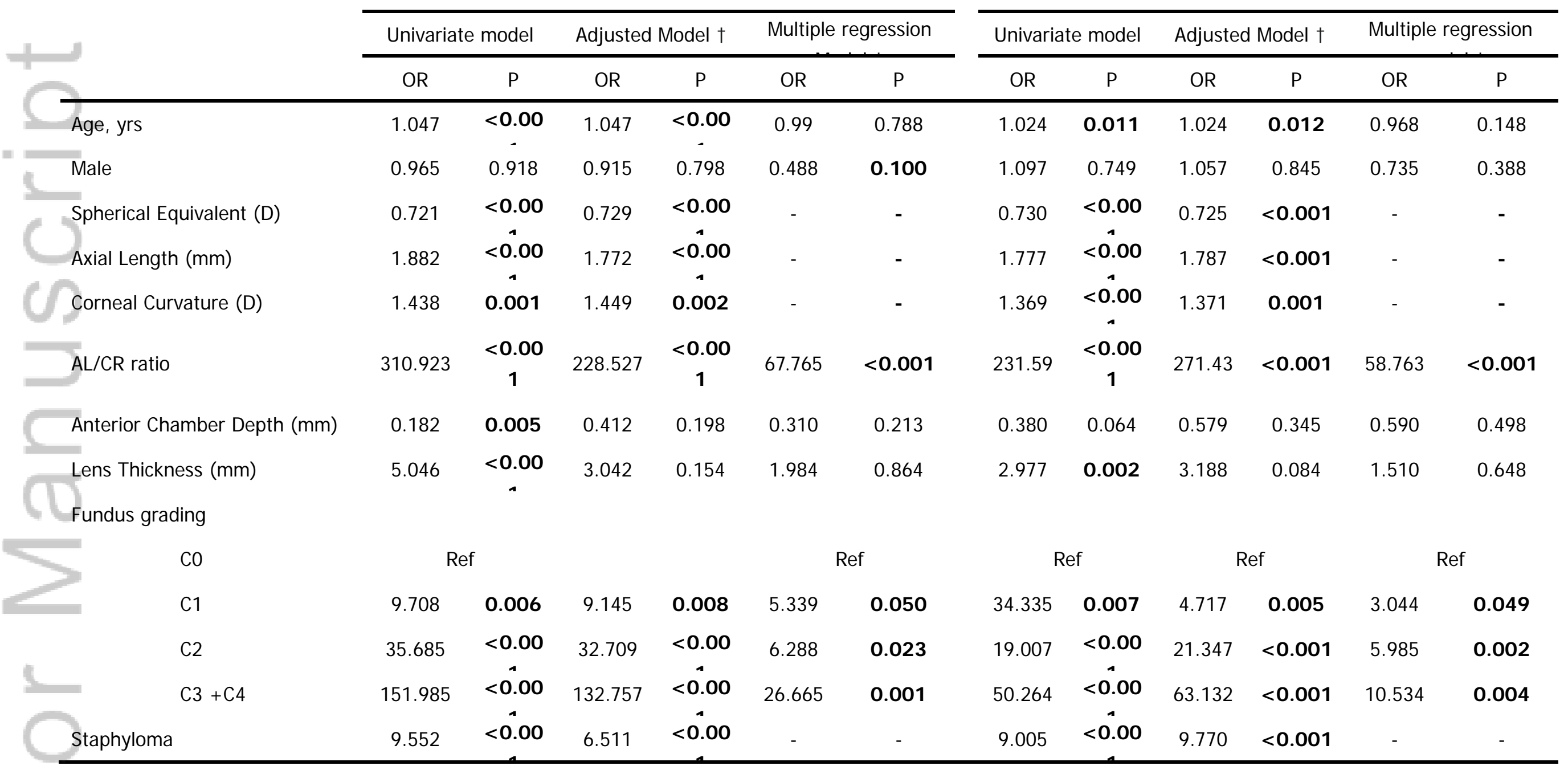

D: Diopter

This article is protected by copyright. All rights reserved. 
† Adjusted by age, gender

‡ Adjusted by age, gender, AL/CR ratio, anterior chamber depth, lens thickness, fundus grading. 
Figure 1: BCVA in different myopic maculopathy lesion categories under WHO and US definitions

BCVA in different myopic maculopathy lesion categories (WHO definition)

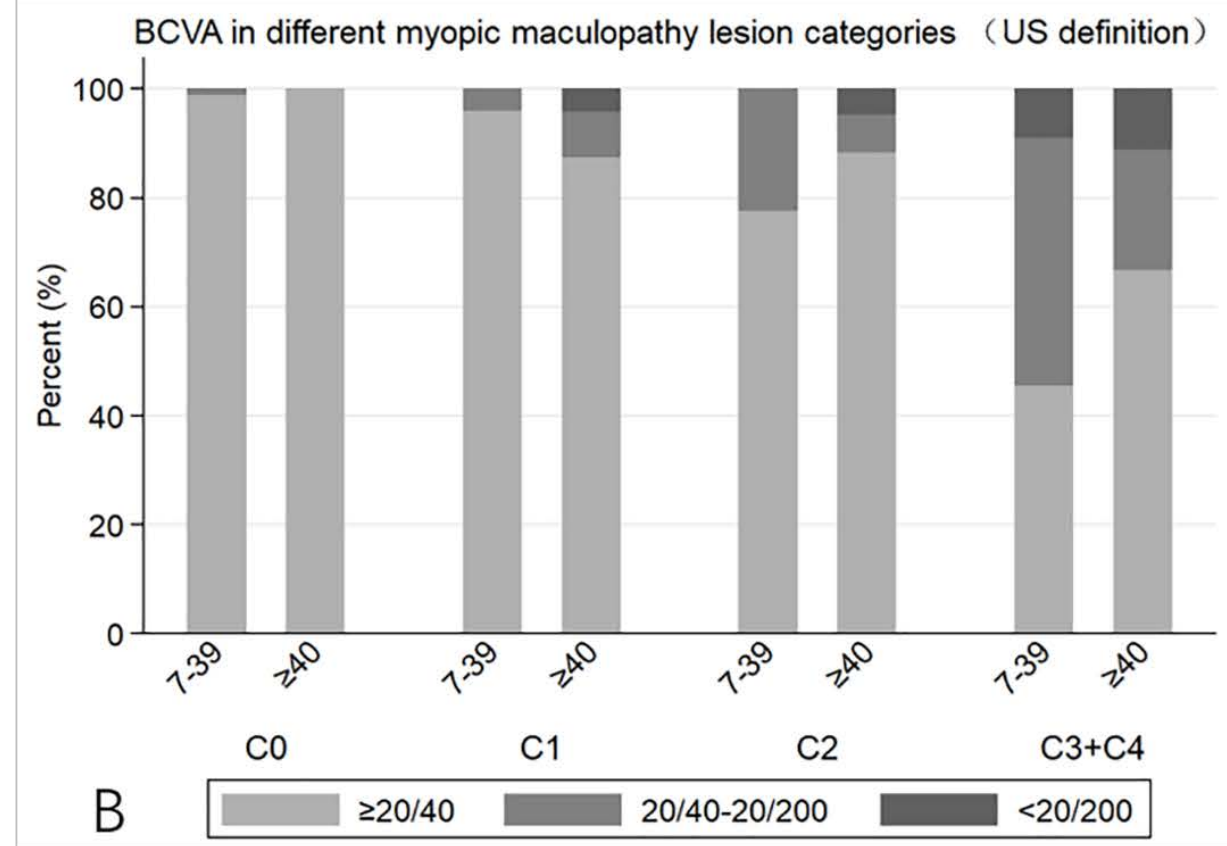

This article is protected by copyright. All rights reserved. 
Supplementary table 1: Rates of uncorrected visual impairment and blindness in worse-seeing eye (Defined by WHO criteria and US criteria) by gender, age, spherical equivalent and axial length.

\begin{tabular}{|c|c|c|c|c|c|c|c|c|c|c|c|c|}
\hline \multirow{3}{*}{ Group } & \multicolumn{6}{|c|}{ Visual Acuity in the Worse-Seeing Eye (WHO) } & \multicolumn{6}{|c|}{ Visual Acuity in the Worse -Seeing Eye (US) } \\
\hline & \multicolumn{3}{|c|}{$<20 / 400$} & \multicolumn{3}{|c|}{$<20 / 60$ and $\geq 20 / 400$} & \multicolumn{3}{|c|}{$<20 / 200$} & \multicolumn{3}{|c|}{$<20 / 40$ and $\geq 20 / 200$} \\
\hline & No. & $\%(95 \% \mathrm{Cl})$ & $P$ & No. & $\%(95 \% \mathrm{Cl})$ & $\mathrm{P}$ & No. & $\%(95 \% \mathrm{Cl})$ & $P$ & No. & $\%(95 \% \mathrm{Cl})$ & $P$ \\
\hline \multicolumn{13}{|l|}{ Gender } \\
\hline Male $(n=410)$ & 166 & $40.5(35.7-45.3)$ & & 244 & 59.5 (54.7-64.3) & & 370 & 90.2 (87.4-93.1) & & 79 & 19.3 (15.4-23.1) & \\
\hline \multirow[t]{2}{*}{ Female $(n=474)$} & 199 & $42.0(37.5-46.4)$ & & 274 & $57.8(53.3-62.3)$ & & 424 & $89.5(86.7-92.2)$ & & 79 & $16.7(13.3-20.0)$ & \\
\hline & & & 0.652 & & & 0.608 & & & 0.698 & & & 0.333 \\
\hline \multicolumn{13}{|l|}{ Age } \\
\hline $7-18(n=426)$ & 127 & $29.8(25.5-34.2)$ & & 298 & $69.9(65.6-74.3)$ & & 361 & $84.7(81.3-88.2)$ & & 103 & $24.2(20.1-28.3)$ & \\
\hline $19-39(n=362)$ & 187 & $51.7(46.5-56.8)$ & & 175 & $48.3(43.2-53.5)$ & & 344 & $95.0(92.8-97.3)$ & & 42 & $11.6(8.3-14.9)$ & \\
\hline \multirow[t]{3}{*}{$40+(n=96)$} & 51 & $53.1(43.0-63.3)$ & & 45 & $46.9(36.7-57.0)$ & & 89 & $92.7(87.4-98.0)$ & & 13 & $13.5(6.6-20.5)$ & \\
\hline & & & $<0.00$ & & & $<0.00$ & & & $<0.00$ & & & $<0.00$ \\
\hline & & & 1 & & & 1 & & & 1 & & & 1 \\
\hline \multicolumn{13}{|l|}{ Spherical equivalent (D) } \\
\hline-6.00 to $-7.99(n=299)$ & 77 & $25.8(20.8-30.7)$ & & 221 & $73.9(68.9-78.9)$ & & 247 & $82.6(78.3-86.9)$ & & 82 & $27.6(22.5-32.7)$ & \\
\hline-8.00 to $-9.99(n=287)$ & 109 & $38.0(32.3-43.6)$ & & 178 & $62.0(56.4-67.7)$ & & 264 & $92.0(88.8-95.1)$ & & 47 & $16.4(12.1-20.8)$ & \\
\hline$<-10.00(n=294)$ & 176 & $59.9(54.2-65.5)$ & & 118 & $40.1(34.5-45.8)$ & & 279 & $94.9(92.4-97.4)$ & & 29 & $9.8(6.4-13.2)$ & \\
\hline \multicolumn{13}{|l|}{ Missing(n=4) } \\
\hline & & & $<0.00$ & & & $<0.00$ & & & $<0.00$ & & & $<0.00$ \\
\hline & & & 1 & & & 1 & & & 1 & & & 1 \\
\hline
\end{tabular}


Axial Length (mm)

$<28.00(n=620)$

28.00-29.99 $(n=199)$

$\geq 30.00(n=63)$

Missing( $n=2)$

\begin{abstract}
$415 \quad 66.8(63.1-70.5)$
$91 \quad 46.0(39.0-53.0)$

$12 \quad 19.0(9.1-29.0)$
\end{abstract}
$20533.0(29.3-36.7)$
81.0 (71.0-90.9)
$540 \quad 87.0$ (84.3-89.6)
$189 \quad 95.5(92.5-98.4)$
$63 \quad 100.0(100.0-$

100.0)
$132 \quad 21.4(18.1-24.6)$

$25 \quad 12.7(8.0-17.4)$

$1 \quad 1.5(0-4.5)$

$$
<0.00
$$

1

Total $(\mathrm{N}=884)$
$<0.00$

1
$<0.00$

1
$<0.00$

1

Supplementary table 2: Rates of best-corrected visual impairment and blindness in worse-seeing eye (Defined by WHO criteria and US criteria) by gender, age, spherical equivalent and axial length in ZOC-BHVI High Myopia Cohort Study. 


\begin{tabular}{|c|c|c|c|c|c|c|c|c|c|c|c|c|}
\hline \multirow{3}{*}{ Group } & \multicolumn{6}{|c|}{ Visual Acuity in the Worse -Seeing Eye (WHO) } & \multicolumn{6}{|c|}{ Visual Acuity in the Worse -Seeing Eye (US) } \\
\hline & \multicolumn{3}{|c|}{$<20 / 400$} & \multicolumn{3}{|c|}{$<20 / 60$ and $\geq 20 / 400$} & \multicolumn{3}{|c|}{$<20 / 200$} & \multicolumn{3}{|c|}{$<20 / 40$ and $\geq 20 / 200$} \\
\hline & No. & $\%(95 \% \mathrm{Cl})$ & $P$ & No. & $\%(95 \% \mathrm{Cl})$ & $\mathrm{P}$ & No. & $\%(95 \% \mathrm{Cl})$ & $\mathrm{P}$ & No. & $\%(95 \% \mathrm{Cl})$ & $P$ \\
\hline \multicolumn{13}{|l|}{ Gender } \\
\hline Male $(n=410)$ & 3 & $0.7(0-1.6)$ & & 37 & $9.0(6.2-11.8)$ & & 7 & $1.7(0.4-3.0)$ & & 56 & $13.7(10.3-16.9)$ & \\
\hline \multirow[t]{2}{*}{ Female $(n=474)$} & 3 & $0.6(0-1.3)$ & & 46 & $9.7(7.0-12.4)$ & & 6 & $1.3(0.3-2.3)$ & & 64 & $13.5(10.4-16.6)$ & \\
\hline & & & 0.858 & & & 0.729 & & & 0.587 & & & 0.946 \\
\hline \multicolumn{13}{|l|}{ Age } \\
\hline $7-18(n=426)$ & 2 & $0.5(0-1.1)$ & & 13 & $3.1(1.4-4.7)$ & & 3 & $0.7(0-1.5)$ & & 32 & $7.5(5.0-10.0)$ & \\
\hline $19-39(n=362)$ & 1 & $0.3(0-0.8)$ & & 50 & 13.8(10.2-17.4) & & 2 & $0.6(0-1.3)$ & & 62 & $17.1(13.2-21.0)$ & \\
\hline \multirow[t]{3}{*}{$40+(n=96)$} & 3 & $3.1(0-6.7)$ & & 20 & $20.8(12.6-29.1)$ & & 8 & $8.3(2.7-14.0)$ & & 26 & $27.1(18.0-36.1)$ & \\
\hline & & & 0.008 & & & $<0.00$ & & & $<0.00$ & & & $<0.001$ \\
\hline & & & & & & 1 & & & 1 & & & \\
\hline \multicolumn{13}{|l|}{ Spherical equivalent (D) } \\
\hline-6.00 to $-7.99(n=299)$ & 0 & 0 & & 5 & $1.7(0.2-3.1)$ & & 0 & 0 & & 10 & $3.3(1.3-5.4)$ & \\
\hline-8.00 to $-9.99(n=287)$ & 2 & $0.7(0-1.7)$ & & 8 & $2.8(0.9-4.7)$ & & 4 & $1.4(0-2.8)$ & & 17 & $5.9(3.2-8.7)$ & \\
\hline$<-10.00(n=294)$ & 4 & $1.4(0-2.7)$ & & 66 & $22.4(17.7-27.2)$ & & 7 & $2.4(0.6-4.1)$ & & 91 & $31.0(25.6-36.3)$ & \\
\hline Missing(n=4) & & & & & & & & & & & & \\
\hline
\end{tabular}


0.251

$<0.00$

1

Axial Length ( $\mathrm{mm})$

$<28.00(\mathrm{n}=620)$

28.00-29. $99(\mathrm{n}=199)$

$\geq 30.00(n=63)$

Missing $(n=2)$
$20.3(0-0.8)$

$2 \quad 1.0(0-2.4)$

$2 \quad 3.2(0-7.6)$
$25 \quad 4.0(2.5-5.6)$

$32 \quad 16.2(11.0-21.3)$

$2641.3(28.8-53.8)$
$<0.00$

1

$3 \quad 0.5(0-1.0)$

$5 \quad 2.5(0.3-4.7)$

$5 \quad 7.9(1.1-14.8)$
$<0.001$

$47 \quad 7.6(5.5-9.7)$

$45 \quad 22.7(16.9-28.6)$

$28 \quad 44.4(31.8-57.1)$

0.062

$<0.00$

$<0.00$

$<0.001$

1

Total $(\mathrm{N}=884)$

$6 \quad 0.7(0.1-1.2)$

$83 \quad 9.4(7.5-11.3)$

1

$13 \quad 1.5(0.7-2.3)$

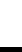

D: Diopter; WHO: World Health Organization criteria; US: United States criteria

This article is protected by copyright. All rights reserved. 


\section{University Library}

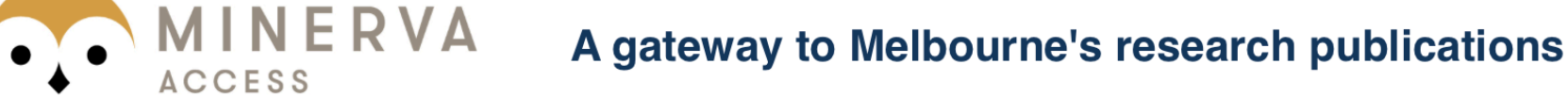

Minerva Access is the Institutional Repository of The University of Melbourne

Author/s:

Jiang, Y;Wang, D;Han, X;Liao, C;Li, Z;Scheetz, J;Jong, M;Sankaridurg, P;He, M

Title:

Visual impairment in highly myopic eyes: The ZOC-BHVI High Myopia Cohort Study

Date:

2020-08

Citation:

Jiang, Y., Wang, D., Han, X., Liao, C., Li, Z., Scheetz, J., Jong, M., Sankaridurg, P. \& He, M. (2020). Visual impairment in highly myopic eyes: The ZOC-BHVI High Myopia Cohort Study. CLINICAL AND EXPERIMENTAL OPHTHALMOLOGY, 48 (6), pp.783-792. https:// doi.org/10.1111/ceo.13779.

Persistent Link:

http://hdl.handle.net/11343/275878 